\title{
The Intertwined Futures of Whales and Humans
}

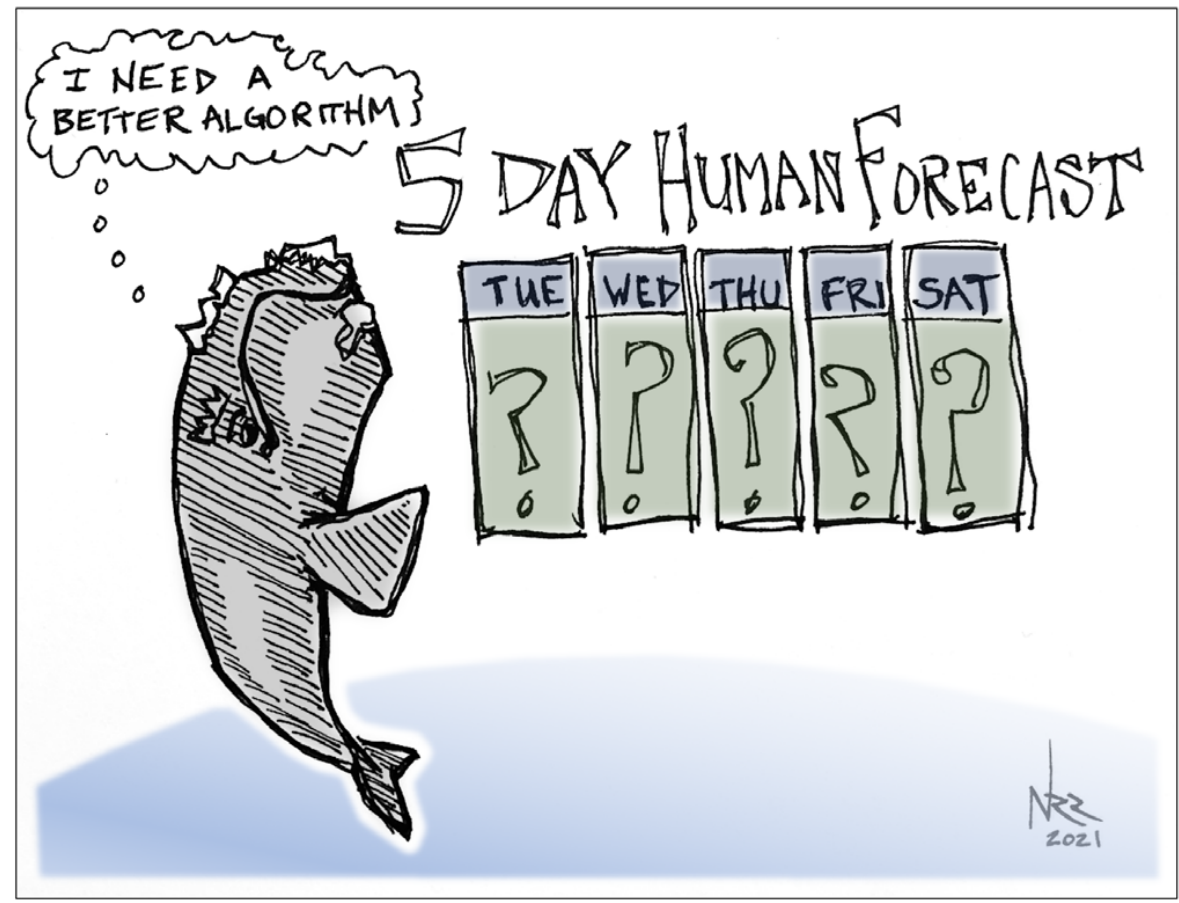

IF YOU COULD somehow ask a North Atlantic right whale what she thinks the future holds, what would she say? Right whales must, in some way, think about the future in order to make survival decisions. As an ocean science community, our eyes are trained increasingly on the future as well. The twin global environmental crises of climate change and biodiversity loss have elevated the science of real-world prediction to one of urgent interest. At timescales ranging from hours to decades, society is asking ocean science for actionable predictions, projections, and forecasts, with the hope of mitigating and adapting to the changing ocean. Meeting this challenge requires more than the ability to predict ocean dynamics.
For highly endangered species like the North Atlantic right whale (Eubalaena glacialis), better foresight might have prepared us for the changes that recently led to a catastrophic unusual mortality event (UME). Predictable oceanographic changes in turn drove changes in right whale migration and calving, reversing what had been a recovery of the species. Now, fewer than 400 of them remain alive. For many of us working in right whale science, policy, and management, we are haunted by questions of how the UME might have been anticipated and prevented and how we might prevent something similar in the future. The oceanography itself, while crucial, is only half of the equation.

As Meyer-Gutbrod et al. (2021, in this issue) detail in their analysis, the oceanographic mechanisms behind the recent changes are well understood by the oceanographic community. Warming has led to shifts in ocean currents like the Gulf Stream, which influence the source of deep-water supply to the Gulf of Maine (Neto et al., 2021). Changes in deepwater conditions alter the availability of right whales' primary prey, Calanus finmarchicus (Record et al., 2019). Without a reliable supply of prey, foraging patterns have changed, broadening the range outside of protected areas, leading to higher mortality (Davies and Brillant, 2019) and reduced calving, and thus putting the species at significant risk of extinction (Meyer-Gutbrod et al., 2021, in this issue). 
Given our knowledge of the oceanographic underpinnings of E. glacialis dynamics, one might then ask: Why aren't we making actionable forecasts for this species? Biological forecasts have moved into the mainstream and are undergoing a "Cambrian Explosion" (Payne et al., 2017). The simple answer to this question is, "we are trying." The science of making forecasts for E. glacialis is vibrant. There are established techniques for forecasting whale locations and population dynamics at weekly (Pendleton et al., 2012), seasonal (Pershing et al., 2009), interannual (Meyer-Gutbrod and Greene, 2018), and multidecadal (Ross et al., 2021) timescales. On top of this, the Canadian Space Agency has recently invested millions of dollars in five projects aimed at detecting E. glacialis and forecasting their locations in real time. Other similar forecasting programs exist (e.g., NOAA's WhaleWatch, https://www. fisheries.noaa.gov/west-coast/marinemammal-protection/whalewatch and the Tandy Center for Ocean Forecasting, https://www.bigelow.org/services/oceanforecasting/), and more are proliferating.

An optimistic interpretation of this body of forecasting work is that we're making progress. We're just not quite there yet. Given a little more time, improved forecasts will be helping us turn the tide for right whale recovery. They could be just a few years or decades away. For those concerned with endangered species, however, getting to the point of usable forecasts has been painstakingly slowand particularly frustrating because of how forecasts could have helped prevent the recent UME.

Many counter that there is too much uncertainty for whale forecasts to be useful, whether forecasting foraging and migration patterns, locations of aggregations, or calving and mortality rates. The bar is set high because of the stakes of the question, and because of the comparison to such familiar high-precision forecasts as those for weather. But the science has been demonstrated, and the predictions for changes that came to pass were already there (e.g., Reygondeau and Beaugrand, 2010; Pendleton et al., 2012). An alternate answer to why aren't we making actionable forecasts? involves taking a step back and thinking about how humans, including scientists and their forecasts, are part of marine systems.

Based on the traditions of Western science, we are accustomed to trying to think about the scientist or observer as distinct from the system of study. The theoretical and experimental underpinnings of modern ecology are based on this assumption. But the single example of right whale population forecasts that is already in regular use contradicts this assumption. Marine mammal management is based on a calculation of potential biological removal (PBR), which relies on a forecast (and forecast uncertainty) of the future population trajectory. The forecast predicts the probability of a certain population level at a certain time

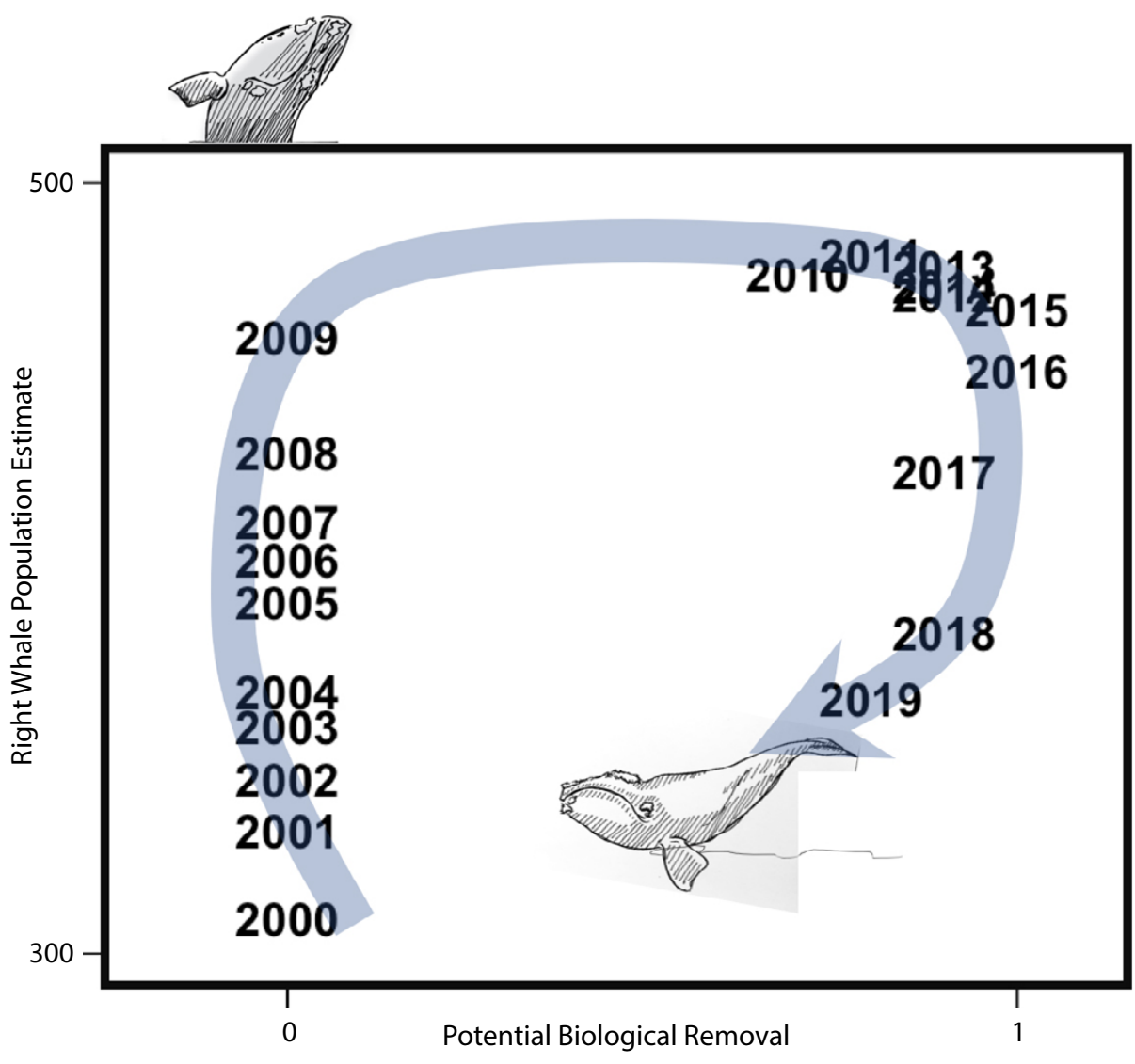

FIGURE 1. Right whale population estimate each year from 2000-2019 versus potential biological removal (PBR) for that year. Evidence is consistent with reflexive dynamics in right whale prediction and management. The PBR is from Pettis et al. (2021), and the population estimates use the method of Pace et al. (2017).
(Taylor et al., 2000), and management decisions are made based on the resulting PBR. A particularly dire forecast will prompt a lowering of PBR and ensuing actions will be aimed at lowering right whale mortality. The hope is that because of the human response, the dire prediction never comes to pass. In essence, the hope is that the dissemination of the forecast will, itself, render the forecast false. This is a dynamic known as reflexivity and is well characterized in the social sciences. It occurs when the dissemination of a prediction affects the outcome of the prediction.

In the case of PBR, reflexivity can work in both directions: a favorable forecast can also lead to an increase in PBR, a relaxing of conservation actions and motives, and a subsequent increase in right whale mortality. This sequence of events is consistent with the past $\sim 20$ years of right whale management (Figure 1). While popula- 
tion dynamics is a well-understood science with a strong mathematical underpinning, the human response, and its effect on mortality, introduces a huge amount of uncertainty. It is the uncertainty around the human response, not the oceanographic dynamics, that makes forecasts so difficult to operationalize well. Even when oceanographic mechanisms are well understood, a lack of understanding of the human response can lead to unintended consequences (Hobday et al., 2019).

The prominence of the role humans play in ocean systems extends further. The Bigelow Laboratory for Ocean Sciences has launched a forecasting center where we aspire to follow the model of knowledge co-production (Cooke et al., 2021), which means we incorporate forecast users, beginning with the initial forecast design steps. This process can reshape questions and lead to surprises. One piece of input that sometimes comes from users in industry is that rather than having a forecast of some ocean ecosystem property, such as whale behavior, they would prefer to have a forecast of management decisions. After all, management decisions, whether in sync with ocean conditions or not, are often what people have to respond to. This idea is not usually in the forefront of ocean forecasting programs, which focus on physical, chemical, or biological state variables in the ocean. But we don't really manage endangered speciesrather, we manage humans. And we try to manage humans in such a way that the interactions between humans and whales will improve the situation.

If we could somehow ask right whales what they would look for in a forecast, they would probably want predictions of what humans are going to do. Thinking of a whale population as an entity separate from the scientist is misleading. To forecast whales, we need to forecast humans. Yes, we need to understand oceanography, copepods, climate, and whales as part of this process. But if we want to protect the species, really, we need to understand ourselves. ¿

\section{REFERENCES}

Cooke, S.J., V.M. Nguyen, J.M. Chapman, A.J. Reid, S.J. Landsman, N. Young, S.G. Hinch, S. Schott, N.E. Mandrak, and C.A. Semeniuk. 2021. Knowledge co-production: A pathway to effective fisheries management, conservation, and governance. Fisheries 46(2):89-97, https://doi.org/ 10.1002/fsh.10512.

Davies, K.T., and S.W. Brillant. 2019. Mass humancaused mortality spurs federal action to protect endangered North Atlantic right whales in Canada. Marine Policy 104:157-162, https://doi.org/10.1016/ j.marpol.2019.02.019.

Hobday, A.J., J.R. Hartog, J.P. Manderson, K.E. Mills, M.J. Oliver, A.J. Pershing, and S. Siedlecki. 2019. Ethical considerations and unanticipated consequences associated with ecological forecasting for marine resources. ICES Journal of Marine Science 76(5):1,244-1,256, https://doi.org/10.1093/ icesjms/fsy210.

Meyer-Gutbrod, E.L., and C.H. Greene. 2018 Uncertain recovery of the North Atlantic right whale in a changing ocean. Global Change Biology 24(1):455-464, https://doi.org/10.1111/ gcb.13929.

Meyer-Gutbrod, E.L., C.H. Greene, K.T.A. Davies, and D.G. Johns. 2021. Ocean regime shift is driving collapse of the North Atlantic right whale population. Oceanography 34(3):22-31, https://doi.org/ 10.5670/oceanog.2021.308

Neto, A.G., J.A. Langan, and J.B. Palter. 2021. Changes in the Gulf Stream preceded rapid warming of the Northwest Atlantic Shelf. Communications Earth \& Environment 2(1):74, https://doi.org/10.1038/s43247-021-00143-5. Pace, R.M. III, P.J. Corkeron, and S.D. Kraus. 2017 State-space mark-recapture estimates reveal a recent decline in abundance of North Atlantic right whales. Ecology and Evolution 7(21):8,730-8,741, https://doi.org/10.1002/ece3.3406.

Payne, M.R., A.J. Hobday, B.R. MacKenzie, D. Tommasi, D.P. Dempsey, S.M. Fässler, A.C. Haynie, R. Ji, G. Liu, P.D. Lynch, and D. Matei. 2017. Lessons from the first generation of marine ecological forecast products. Frontiers in Marine Science 4:289, https://doi.org/10.3389/ fmars.2017.00289.

Pendleton, D.E., P.J. Sullivan, M.W. Brown, T.V.N. Cole, C.P. Good, C.A. Mayo, B.C. Monger, S. Phillips, N.R. Record, and A.J. Pershing. 2012. Weekly predictions of North Atlantic right whale Eubalaena glacialis habitat reveal influence of prey abundance and seasonality of habitat preferences. Endangered Species Research 18(2):147-161, https://doi.org/10.3354/esr00433.

Pershing, A.J., N.R. Record, B.C. Monger C.A. Mayo, M.W. Brown, T.V.N. Cole, R.D. Kenney, D.E. Pendleton, and L.A. Woodard. 2009. Modelbased estimates of right whale habitat use. Marine Ecology Progress Series 378:245-257, https://doi.org/10.3354/meps07829.

Pettis, H.M., R.M. Pace III, and P.K. Hamilton. 2021. North Atlantic Right Whale Consortium 2020 annual report card. North Atlantic Right Whale Consortium, Boston, MA, https://www.narwc.org/ report-cards.html.

Record, N.R., J.A. Runge, D.E. Pendleton, W.M. Balch, K.T. Davies, A.J. Pershing, C.L. Johnson, K. Stamieszkin, R. Ji, Z. Feng, and S.D. Kraus. 2019. Rapid climate-driven circulation changes threaten conservation of endangered North Atlantic right whales. Oceanography 32(2):162-169, https://doi.org/10.5670/oceanog.2019.201.
Reygondeau, G., and G. Beaugrand. Future climatedriven shifts in distribution of Calanus finmarchicus. 2010. Global Change Biology 17(2):756-766, https://doi.org/10.1111/j.1365-2486.2010.02310.x.

Ross, C.H., D.E. Pendleton, B. Tupper, D. Brickman, M.A. Zani, C.A. Mayo, and N.R. Record. 2021. Projecting regions of North Atlantic right whale, Eubalaena glacialis, habitat suitability in the Gulf of Maine for the year 2050. Elementa: Science of the Anthropocene 9(1):00058, https://doi.org/10.1525/ elementa.2020.20.00058.

Taylor, B.L., P.R. Wade, D.P. De Master, and J. Barlow. 2000. Incorporating uncertainty into management models for marine mammals. Conservation Biology 14(5):1,243-1,252, https://doi.org/ 10.1046/j.1523-1739.2000.99409.x.

\section{AUTHOR}

Nicholas R. Record (nrecord@bigelow.org) is Senior Research Scientist and Director, Tandy Center for Ocean Forecasting, Bigelow Laboratory for Ocean Sciences, East Boothbay, ME, USA.

\section{ARTICLE CITATION}

Record, N.R. 2021. The intertwined futures of whales and humans. Oceanography 34(3):16-18, https://doi.org/10.5670/oceanog.2021.314.

\section{COPYRIGHT \& USAGE}

This is an open access article made available unde the terms of the Creative Commons Attribution 4.0 International License (https://creativecommons.org/ licenses/by/4.0/), which permits use, sharing, adaptation, distribution, and reproduction in any medium or format as long as users cite the materials appropriately, provide a link to the Creative Commons license, and indicate the changes that were made to the original content. 